\title{
An unusual interference in parathormone assay caused by anti-goat IgG: a case report
}

\author{
Etienne Cavalier*, Pierre Delanaye, Agnès \\ Carlisi, Jean-Paul Chapelle and Julien Collette \\ Department of Clinical Chemistry, Centre Hospitalier \\ Universitaire de Liège, University of Liège, Liège, \\ Belgium
}

Keywords: analytical interference; human anti-animal antibodies; parathormone.

We report the case of a 29 -year-old woman, working as a nurse, who underwent a blood analysis to monitor hypothyroidism. In addition to the "classical" parameters, her physician ordered a parathormone (PTH) determination. The result of the PTH test was found to be $>2000 \mathrm{pg} / \mathrm{mL}$ (normal range: $12-54 \mathrm{pg} / \mathrm{mL}$ ) with the Liaison analyser (Diasorin, Stillwater, MN, USA). As recently published (1), we considered this result as "spurious" and we treated the sample with HBR 1 (Scantibodies, Santee, CA, USA) and RF-Absorbent (IBL, Hamburg, Germany) to remove a possible interference due to human anti-animal antibodies (HAAA) and rheumatoid factor (RF), respectively. We also determined PTH with another method (Roche Elecsys, Mannheim, Germany). We observed that the result remained unchanged after HBR treatment, whereas PTH dramatically fell to $40 \mathrm{pg} / \mathrm{mL}$ after anti-RF treatment. With the Elecsys analyser, the PTH was also normal $(24 \mathrm{pg} / \mathrm{mL})$. We thus suspected an interference due to RF, but the patient neither suffered from rheumatoid arthritis (and other autoimmune diseases), nor was positive when we tested for RF (BN2, Siemens, Marburg, Germany). To explore the cause of this interference with the Liaison analyser, we then performed a chromatographic separation with a Superdex 200 HR 10/30 column (Amersham Biosciences, Piscataway, NJ, USA) and we concluded that there was PTH reactivity in the fraction that corresponded to the molecular weight of the lgGs. This confirmed the results of the RF-Absorbent treatment, which, indeed, is a treatment of the sample with anti$\lg G$ antibody.
As the antibodies used for the PTH Liaison analyser are polyclonal goat antibodies (whereas Roche Elecsys use monoclonal mouse antibodies), we suspected that there was anti-goat lgG present in the serum of the patient that could interfere with the assay. To confirm this hypothesis, we incubated $400 \mu \mathrm{L}$ of the patient's serum with $40 \mu \mathrm{L}$ of goat serum. In this condition, we observed that PTH dropped from $>2000$ to $41 \mathrm{pg} / \mathrm{mL}$.

Human anti-animal antibodies are a known cause of interferences in immunoassays (2). This patient had no obvious reason to present anti-goat antibodies (any animal contact, professional exposition, coeliac disease, drug, vaccination or blood transfusion). She did not eat goat's cheese or drink milk. A possible cause could be a pregnancy 3 years prior, even if she was primiparous (3). Even if the manufacturers include in the inserts of the kits that this type of interference remains possible, one should be careful when interpreting the results of any immunoassay. We must keep in mind the tragic outcomes that can be observed with these interferences (4). Indeed, these antibodies can give spurious results, leading to unnecessary cost-effective and stressful extra investigations.

Conflict of interest: None.

\section{References}

1. Cavalier E, Carlisi A, Chapelle JP, Delanaye P. False positive PTH results: an easy strategy to test and detect analytical interferences in routine practice. Clin Chim Acta 2008;387:150-2.

2. Kricka LJ. Human anti-animal antibody interferences in immunological assays. Clin Chem 1999;45:942-56.

3. Hawkins BR, Saueracker GC, Dawkins RL, Davey MG, O'Connor KJ. Population study of heterophile antibodies. Vox Sang 1980;39:339-42.

4. Rotmensch S, Cole LA. False diagnosis and needless therapy of presumed malignant disease in women with falsepositive human chorionic gonadotropin concentrations. Lancet 2000;355:712-5.

\footnotetext{
* Corresponding author: Dr Etienne Cavalier, Department of Clinical Chemistry, University Hospital of Liege, University of Liege, Domaine du Sart-Tilman, Bâtiment B35, 4000 Liege, Belgium

Phone: +32-43667692, Fax: +32-43667691,

E-mail: Etienne.cavalier@chu.ulg.ac.be
} 